\title{
Investigation of the effect of diazinon on CatSper 1 gene expression, sperm motility and germinal epithelium thickness in adult male mice
}

Hamid Reza Faragnezhad ${ }^{1}$, Shabnam Mohammadi ${ }^{2}$, Seyed Morteza Seifati ${ }^{3}$, Atena Mansouri ${ }^{4}$, Reyhaneh Sadat Mahmoodia ${ }^{5}$

1.Msc.Student of Biology, Medical Biotechnology Research Center, Ashkezar Branch, Islamic Azad University, Ashkezar, Yazd, Iran. ORCID ID: 0000-0003-0789-8047

2. Assistant Professor of Anatomy, Neurogenic Inflammation Research Center, Mashhad University of Medical Sciences, Mashhad, Iran (Corresponding Author). Tel: 05138002459, Email: mohammadish@mums.ac.ir. ORCID ID: 0000-0002-2352-286X

3. Assistant Professor of Biology, Medical Biotechnology Research Center, Ashkezar Branch, Islamic Azad University, Ashkezar, Yazd, Iran. ORCID ID: 0000-0002-8505-5267

4. PhD. Student of Nanotechnology, Immunology Research Center, Mashhad University of Medical Sciences, Mashhad, Iran. ORCID ID: 0000-0003-0456-675X

5. PhD. Student of Immunology, Immunology Research Center, Mashhad University of Medical Sciences, Mashhad, Iran. ORCID ID: 0000-0002-0003-9015

\section{ABSTRACT}

Background and Aim: Genetic changes and mutations in the genes involved in spermatogenesis can occur by environmental and congenital factors. Considering, the extensive use of diazinon in the farms and because we found no study on the effects of diazinon on the expression of CatSper1 gene, a key element of male fertility, we decided to perform this study in order to determine the effects of different doses of diazinon on CatSper1 gene expression, sperm motility and thickness of seminiferous tubules in adult male mice.

Materials and Methods: Twenty-four adult male Balb/c mice were randomly divided into four groups. The control group did not receive any injection. The sham group received diazinon solvent. Diazinon1 group received $7.5 \mathrm{mg} / \mathrm{kg}$ and, diazinon group 2 received 30 $\mathrm{mg} / \mathrm{kg}$ of diazinon intraperitoneally, once a day for 2 weeks. After 35 days, we studied the sperms from the molecular and histological aspects and sperm motility was evaluated.

Results: Sperm motility was significantly decreased in diazinon $1(\mathrm{P}$-value $=0.001)$ and diazinon $2(\mathrm{P}$-value $=0.001)$ groups compared to that in the control group. Gene expression in diazinon group 1 and diazinone group $2(\mathrm{P}$-value $=0.002)$ was significantly lower than that in the control group. Histological examination also showed that diazinon treatment reduced germinal epithelium thickness and led to vacuole formation and degeneration. Epithelial thickness was significantly decreased in diazinon group $1(\mathrm{P}$-value $=0.003)$ and diazinon group $2(\mathrm{P}$-value $=0.006)$ in comparison to that in the control group.

Conclusion: Diazinon affects male fertility by reduction in sperm motility and degenerative changes in germinal epithelium. It also, decreases expression of CatSperl gene, a key gene in fertility.

Keywords: CatSper, Sperm, Diazinon, Mouse

Received: Feb 3,2019

Accepted: Nov 9,2019

How to cite the article: Hamid Reza Faragnezhad, Shabnam Mohammadi, Seyed Morteza Seifati, Atena Mansouri, Reyhaneh Sadat Mahmoodian. Investigation of the effect of diazinon on CatSper 1 gene expression, sperm motility and germinal epithelium thickness in adult male mice. SJKU 2020; 24 (6): 68-78

Copyright $(2018$ the Author (s). Published by Kurdistan University of Medical Sciences. This is an open access article distributed under the terms of the Creative Commons Attribution-Non Commercial License 4.0 (CCBY$\mathrm{NC}$ ), where it is permissible to download, share, remix, transform, and buildup the work provided it is properly cited. The work cannot be used commercially without permission from the journal 


\title{
بررسى اثر ديازينون بر بيان زن CatSper 1 تحر اسير م و ضخامت إبى تليوم زرمينال در موش نر بالغ تحرك
}

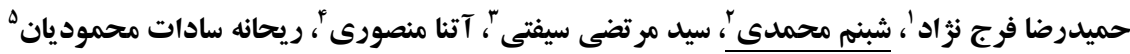

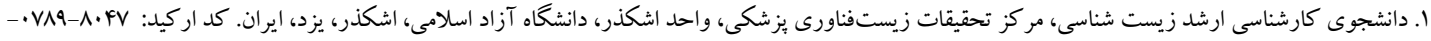

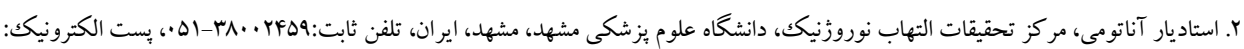

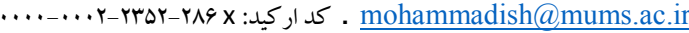 \\ r.باستاديار زيست شناسى، مركز تحقيقات زيستفناورى يزشكى، واحد اشكذر، دانشكاه آزاد اسلامى، اشكذر، يزد، ايران. كد اركيد:

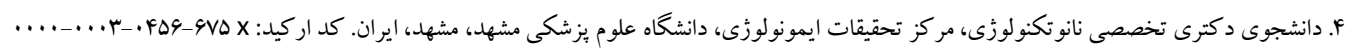

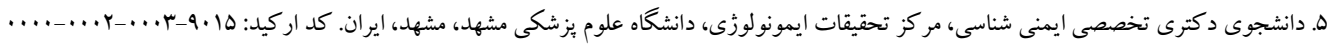

جـكيده

زمينه و هدف: تغييرات زُنتيكى و مو تاسيون زنهاى مؤثر در اسبرماتوزنز از جمله عواملى هستند كه مىتواند ناشى از عوامل

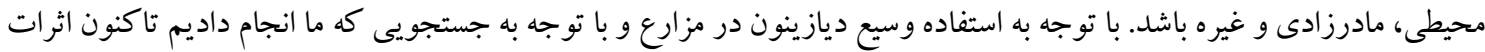
ديازينون بر بيان زن CatSper1 كه از زنهاى كليدى در بارورى مرد است بررسى نشده است. لذا هدف از تحقيق حاضر تعيين

اثرات دوزهاى مختلف ديازينون بر بيان زن هatSper1، تحر كك اسيرم و ضخامت توبول هاى اسيرم ساز در موش نر برد بالغ بود.

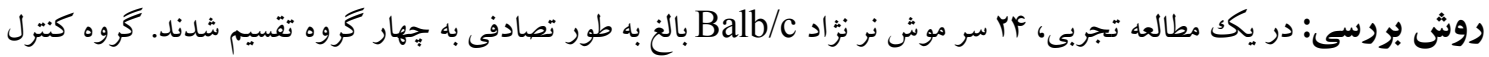

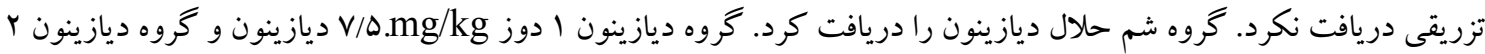

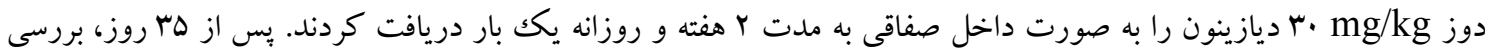
مولكولى، هيستولوزيكى و تحر كك اسبرم انجام شد.

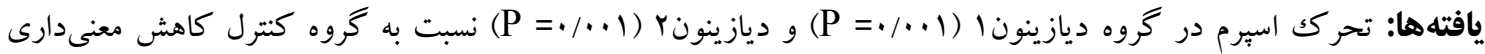

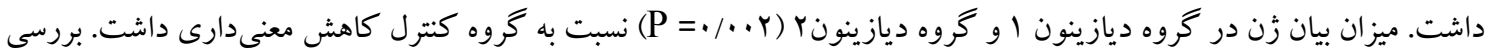

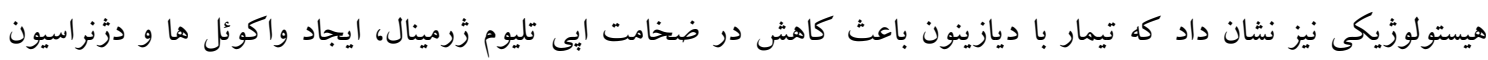

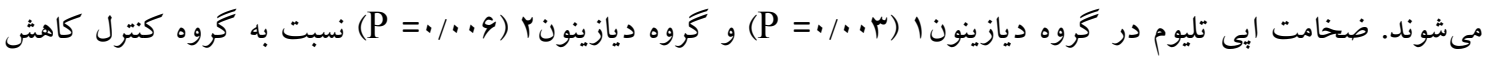
معنى دارى داشت.

CatSper1 نتيجه كيرى: ديازينون با كاهش تحر كك اسبرم و ضخامت إيتليوم زرمينال بر بارورى اثر مى گذارد. به علاوه بيان زدن

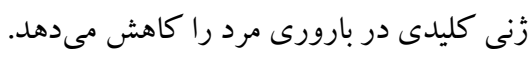

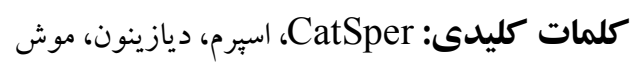

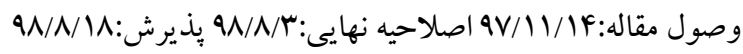


بارورى اسبرم دارنـد و شـامل خـانو اده زنسى CatSper1 تـا CatSper $\beta$ و CatSper4 CatSper بهور اختصاصى در بيضهـ بيـان مى شـوند(V)

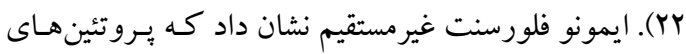
CatSper 1, 2

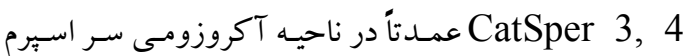

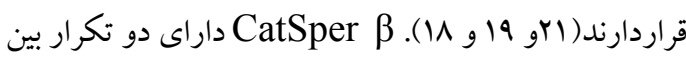
غشايى و CatSper J داراى يكك تكرار بين غشايى است و در ناحيه اصلى دم اسبرم قرار دارند(Y و و (Y).

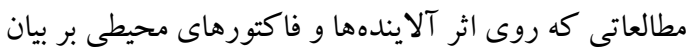

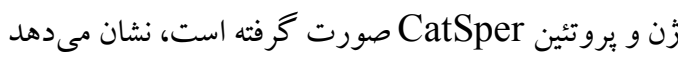

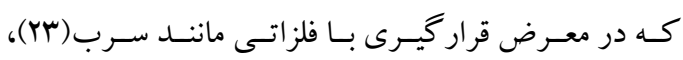

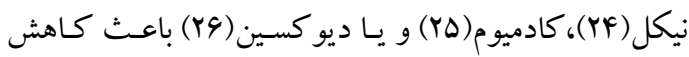

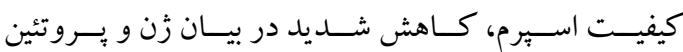
CatSper

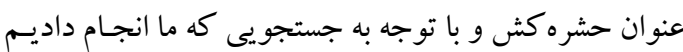

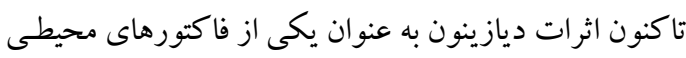

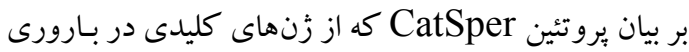

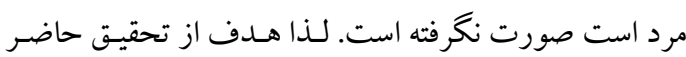

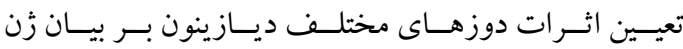
CatSper1

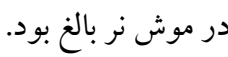

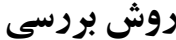

نوع مطالعه تجربى بود كه بـراى انجام آن، از YF سـر مـوش

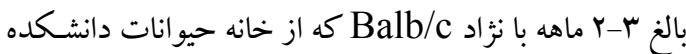

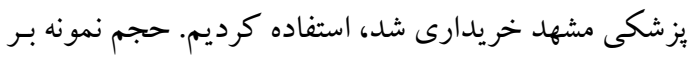

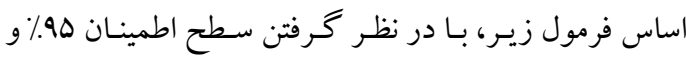

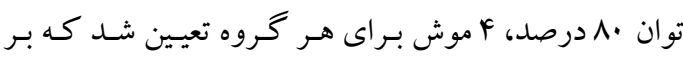

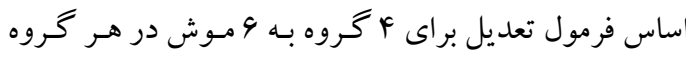

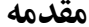

بر اساس تحقيقات انجام شده، حـدود نيمى از مشكلات در

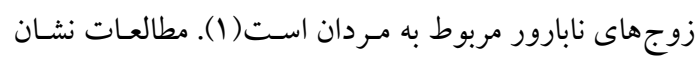

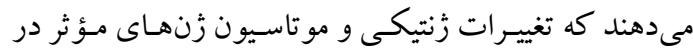

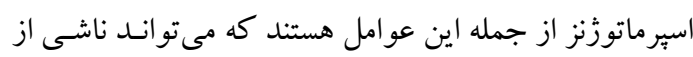

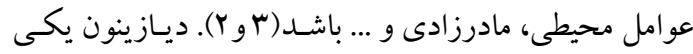

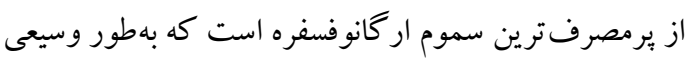

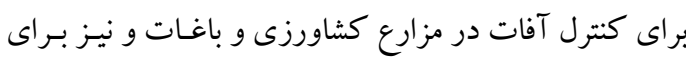

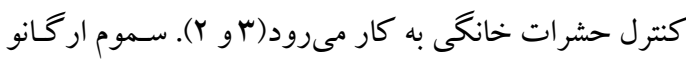

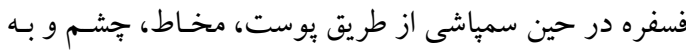

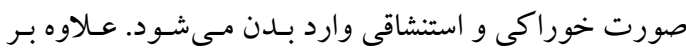

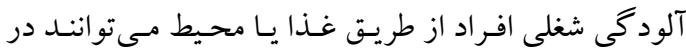

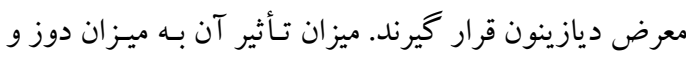

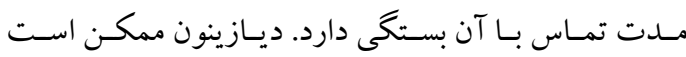

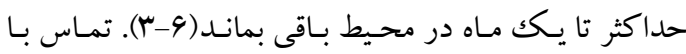

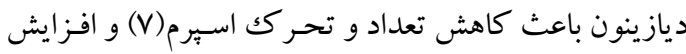

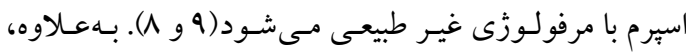

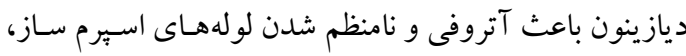

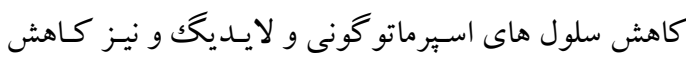

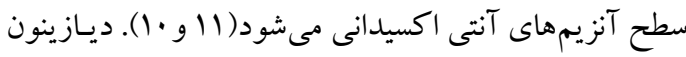

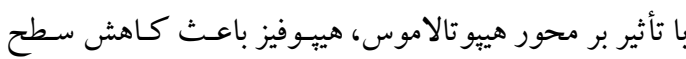

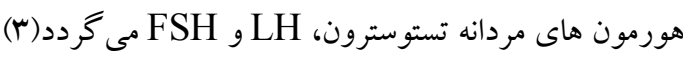

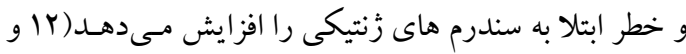

از طرفى تنظيم غلظت كلسيم درونسلولى براى اسبرماتورنز،

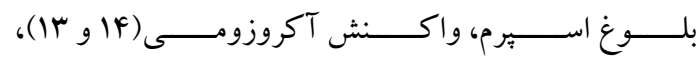

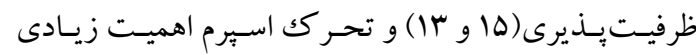

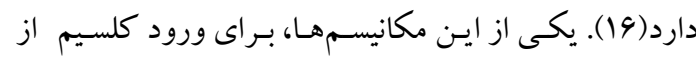

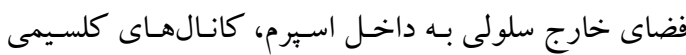

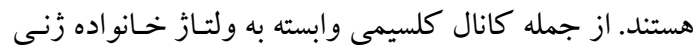
CatSper 
سلولهاى متحرك شمارش شـــ اسـبرمهـاى بـ تحر كك و

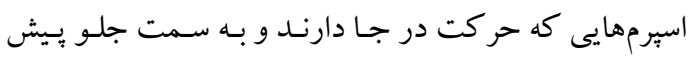

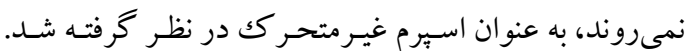

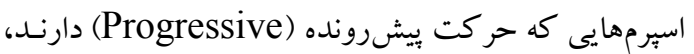

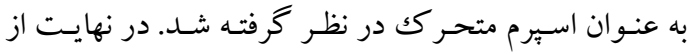
فرمول زير استفاده گرديد(YV).

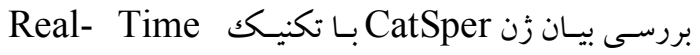

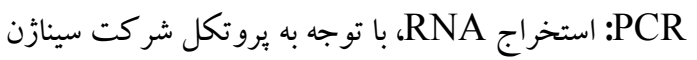

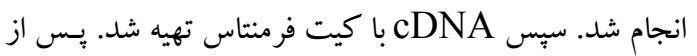

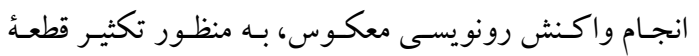
موردنظر واكنش PCR روى محصول RT انجام و زلهــا

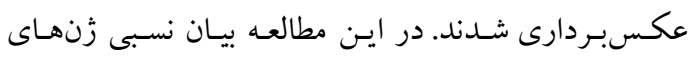
CatSper1

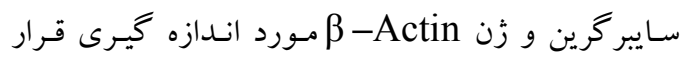
كرفـت.واكـنش Real-Time PCR توسـط دستيكاه Applied Biosystems شد: تعداد مناسب سيكل PCR به صورت:

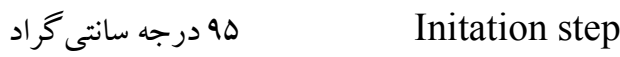
. ادقيقه ا ميكل

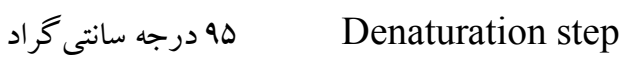
ro 94 Annealing step

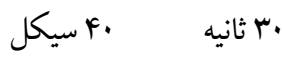
Extention step r آنانيه براى آناليز دادهها از روش pfaffi و همكاران مطابق فرمول

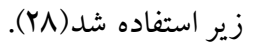

افزايش يافتـ(YV). لـذا حجـم نمونـه كـل YY مـوش تعيـين كرديد. $n=1+2 C\left(\frac{s}{d}\right)^{2}$

$=1+2 * 7.85\left(\frac{0.212}{0.556}\right)^{2}$ $\approx 4$

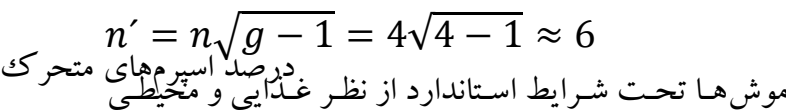

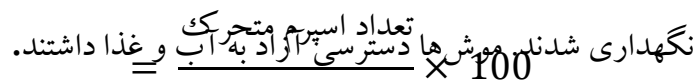

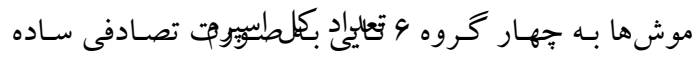

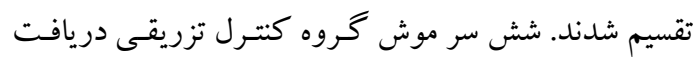

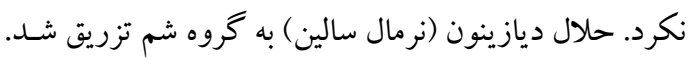

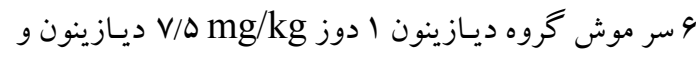

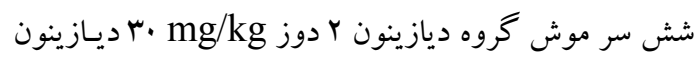

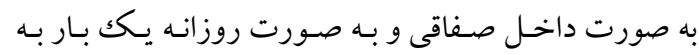

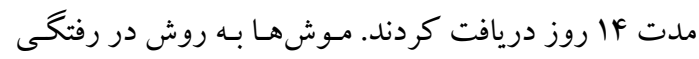

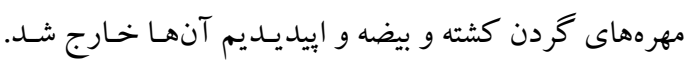

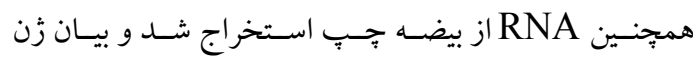
يروتئين CatSper بس از انجام تكنيكك - Real-Time

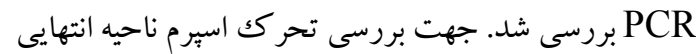

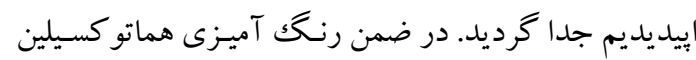
ائوزين بافت بيضه راست جهت بررسى ضخامت إيى تليوم

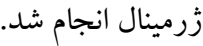

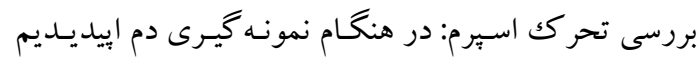

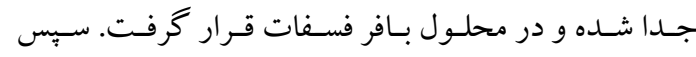

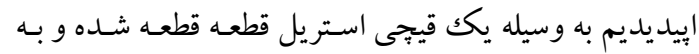

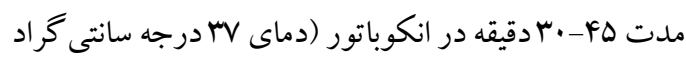

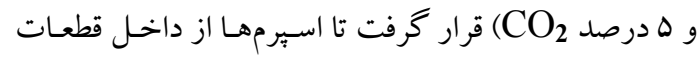

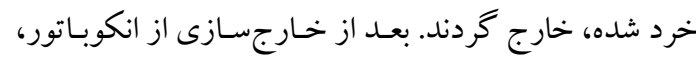

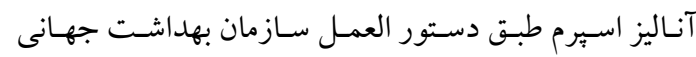
و بـه كمـك لام نئوبـار انجـام شــ(YVHO)

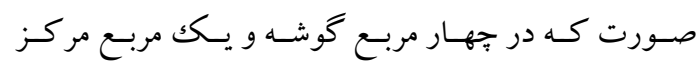


آناليز آمارى: بعـــ از اطمينـان از نرمـال بـودن توزيع دادهاى كمى، با استفاده از تحليل واريانس يككطرفه (ANOVA) و آزمـون تعقيبـ تـوكى تجزيـه و تحليـل لازم انجـام شـــ.

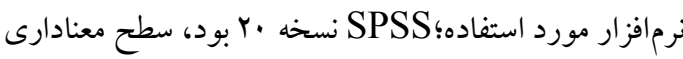
ها درصد براى مقايسه گروهها در نظر خرفته شد.

يافتهها

بررسى درصد تحر كك اسبرم در گروههـاى مختلف آزمـون: در مقايسه كلى تفاوت معنىدارى بين ميزان تحر كك اسبرم

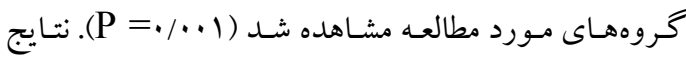

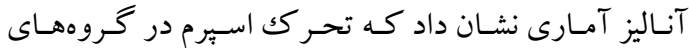

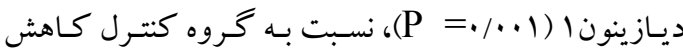
معنسى دارى داشـت. بـه عـلاوه، تحسر كك اسـبرم در گــروه

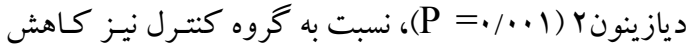

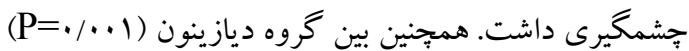
با كروه شم تفاوت معنى دارى مشاهده شد. به علاوه، آزمون آمارى اختلاف معنىدارى بين ميزان تحر كك اسبرم در گروه

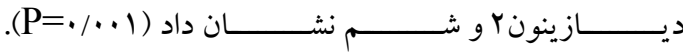

$$
\left(E_{\text {target }}\right)^{\Delta C T} \text { target }(\text { controi-sainple })
$$

Ratio $=$

$$
\left(E_{\text {ref }}\right)^{\Delta C T_{\text {ref }}}{ }^{\text {(conirol-scmple) }}
$$

مطالعه هيستولوزيكى ضخامت إيتليوم زرمينال: آمادهسـازى بافتها شامل مراحل تثبيت، آبخيرى با الكل، شفاف سازى با

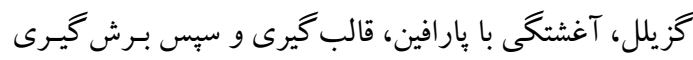

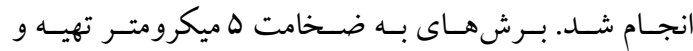

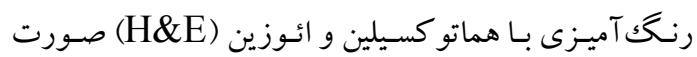

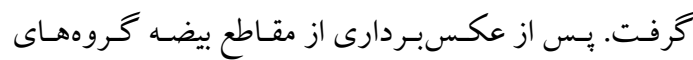

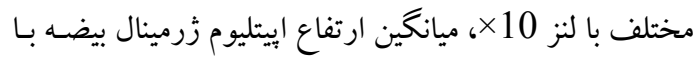

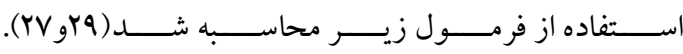

$$
H=\frac{V_{V}}{S_{V}}
$$

II

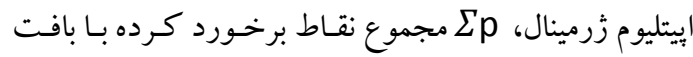
بضه ور/p طول خط يروب در مقياس واقعى بافت.

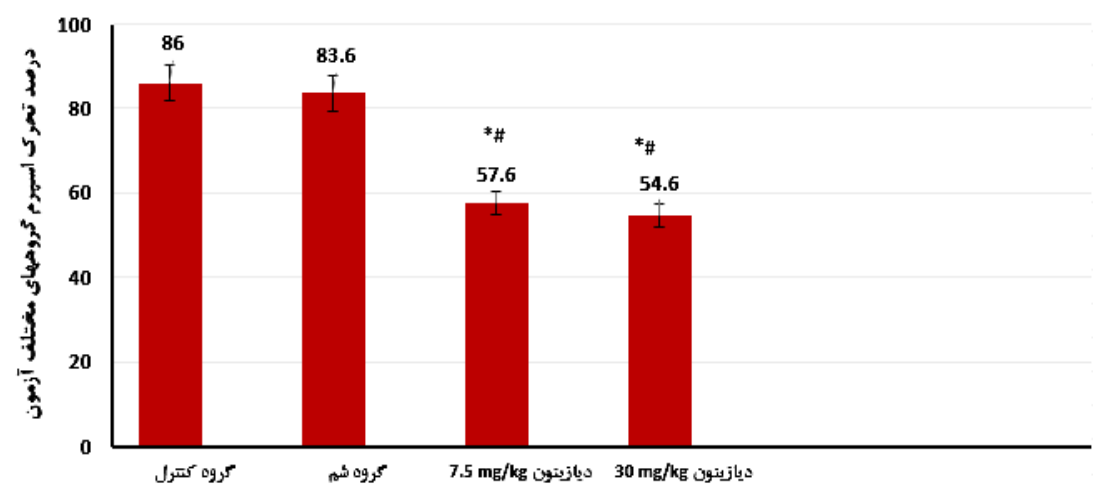

نمودار ا. درصد تحرك اسيرم در گروههاى مختلف آزمون

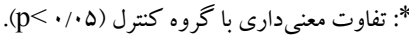

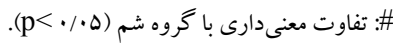


كنترل كاهش معنى دارى داشت. به علاوه، بيان زُن در گروه

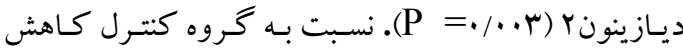

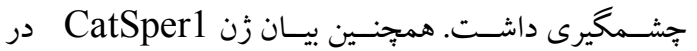

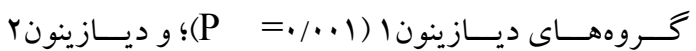

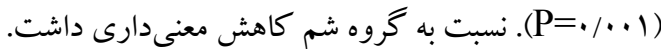

بررسى ميزان بيـان زن CatSper1 در گروههاى مختلف

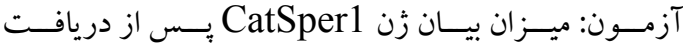

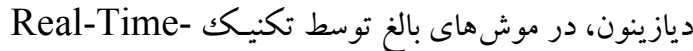

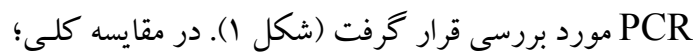
تفاوت معنىدارى بين ميزان بيان زن خروههاى مـورد مطالعه

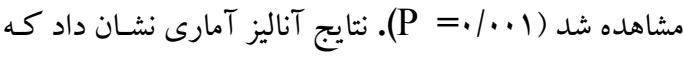

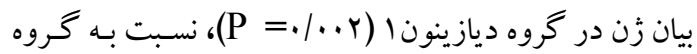

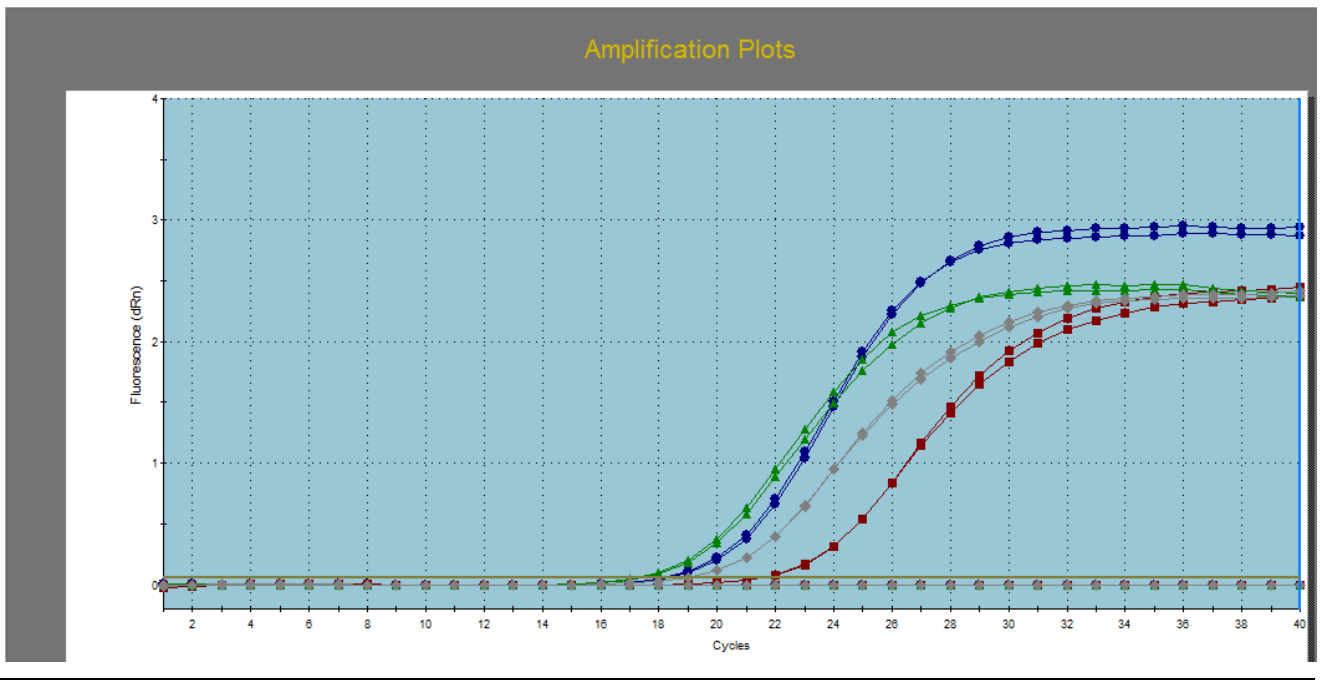

شكل ا. تصوير منحنى real-time PCR بهدست آمده از نمونهها، كه مقايسه بين گروهها را نشان مىدهد.

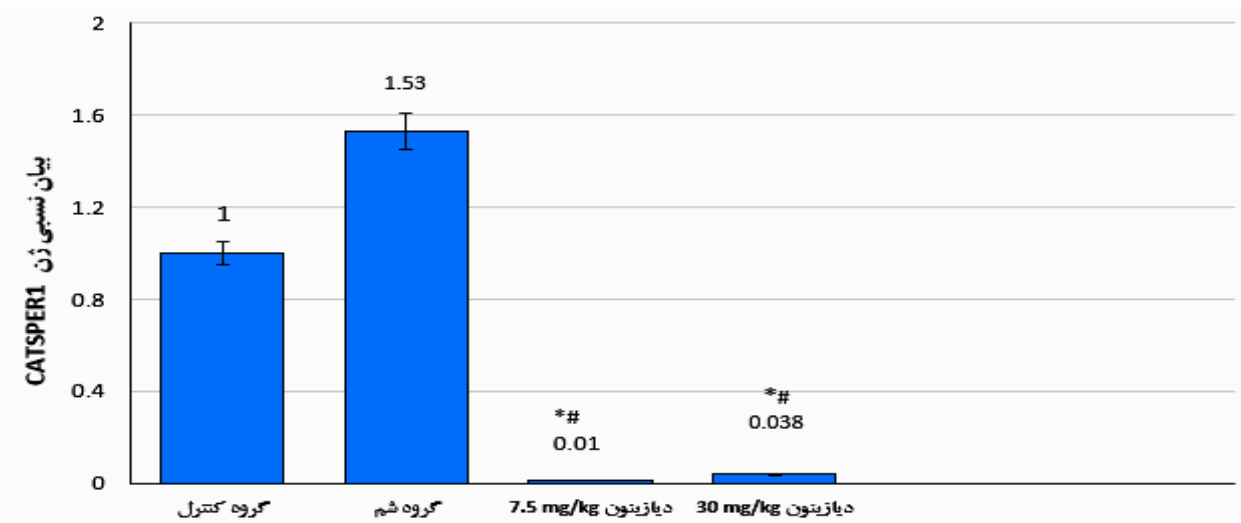

نمودار r. ميز ان بيان زن CatSper1 در گروههاى مختلف آزمون 
بررسى ضخامت ايى تليوم زرمينـال در گروههــاى مختلف آزمون: به منظور بررسى اثر ديازينون بر بافـت بيضـه، مقـاطع

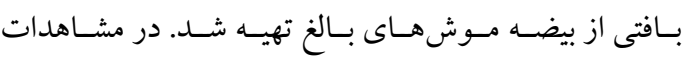
ميكروسكوبى، بيضه مـوشهـاى گرـروه كنتـرل و شـم ظـاهر طبيعى داشته، شامل مجارى منى ساز و بافت بينـابينى طبيعى

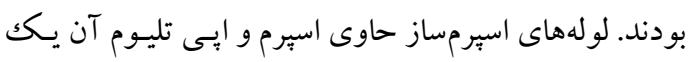
دست و حساوى استِرم بـود (شـكل r الـف و ب). در بيضـه موشهاى گروه دريافت كننده ديازينون كاهش در اسبرماتيد و اسبرم بالغ، واكوئليزاسيون و نكروز در ايى تليوم زرمينال به جشم مى خورد. به علاوه، فضـاى بينـابينى افز ايش يافته بـود (شـكل r ج - د). در مقايسـه كلى؛ تفـاوت معنسى دارى بـين ميز ان ضخامت ايى تليـوم زرمينـال گَروههـاى مـورد مطالعـه

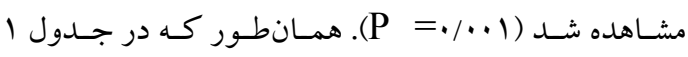
ملاحظه مى كنيد، ضـخامت إيى تليـوم در كروه ديـازينونا

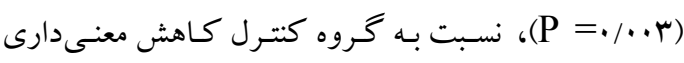
داشت. ضخامت ايى تليوم در گروه ديازينون (4 = (P = (4) نيز نسبت به كروه كنترل كاهش معنىدارى داشت. همجنين بين كاهش در ضـخامت ايسى تليـوم زرمينـال در كروههـاى

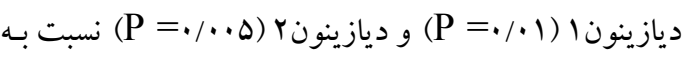
كروه شم مشاهده شد. 

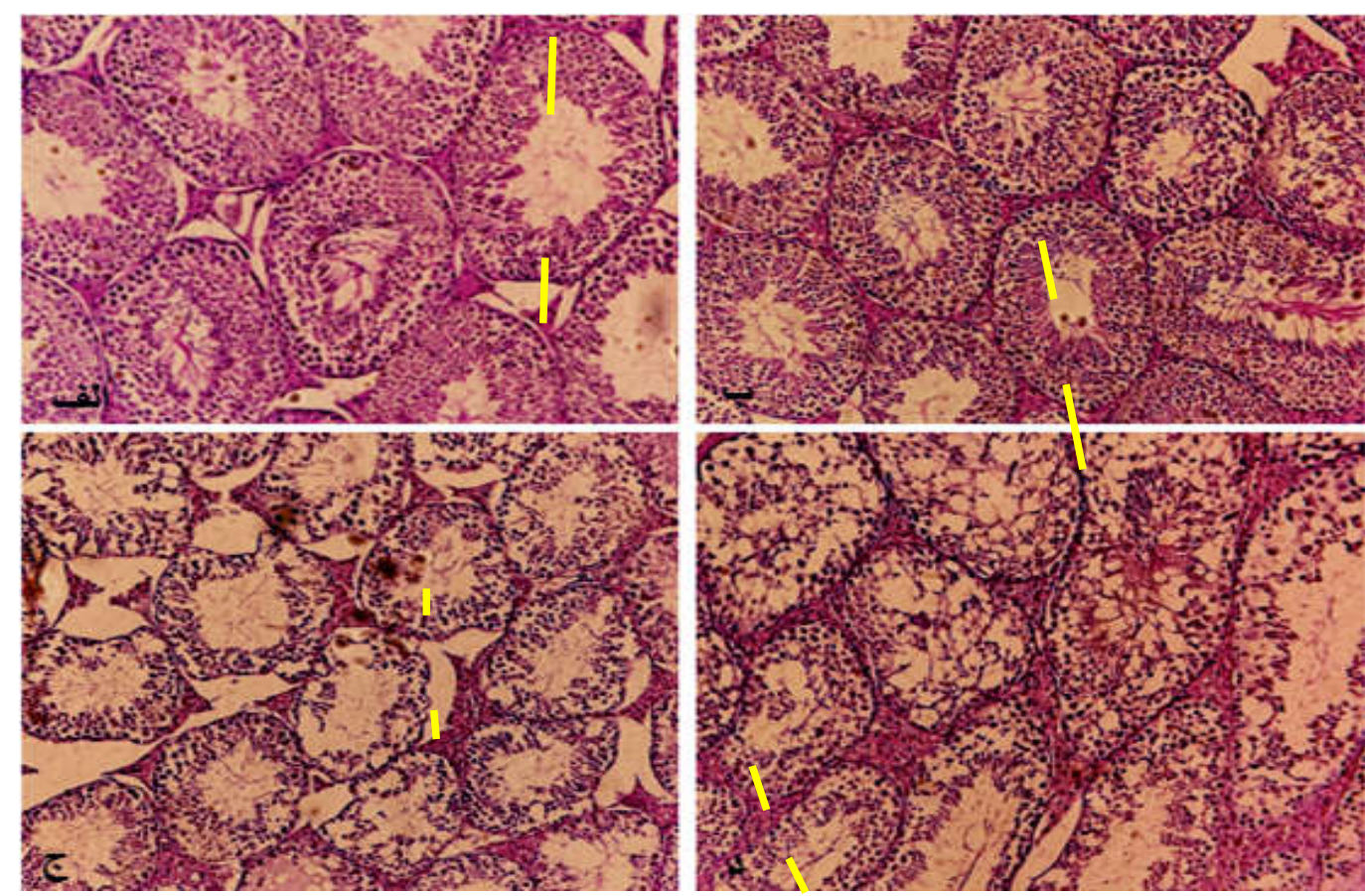

شكل r. تصوير مقطع عرضى لولههاى اسيرم ساز به ترتيب در گروه كنترل (الف)، گروه شم (ب)، گروه ديازينون ا(ج) و گروه ديازينون Y

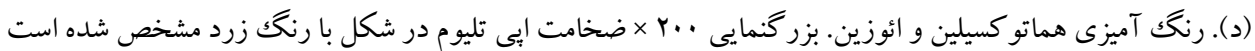

جدول ا. ضخامت ايى تليوم زرمينال در گروههاى مختلف آزمون

\begin{tabular}{|c|c|c|c|}
\hline كروه ديازينون r & گروه ديازينون 1 & كروه شم & كروه كنترل \\
\hline \#** $\Gamma / / 9 V \pm 1 / V q$ & $\# * F^{\prime} / / Y G \pm \Delta / Y \Delta$ & $q \Gamma / \Delta \Delta \pm F / \mu q$ & $G r / V 1 \pm r / 4 q$ \\
\hline
\end{tabular}

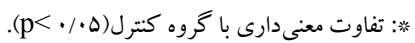

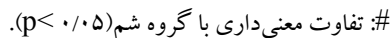


كيفيت اسبرم و افزايش استرس اكسيداتيو شد(ب)). همين محققان گزارش كردند تجويز نيكل و كادميوم نيز بر بيان

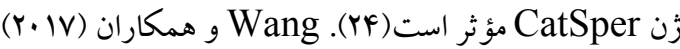
كزارش كردند كه دوزهاى ·، ·ا، •ه و •هT ميكرومول كلريد كادميوم باعث كاهش زندهماندن، تحر كت و واكنش

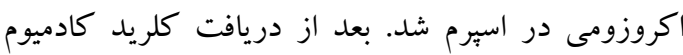

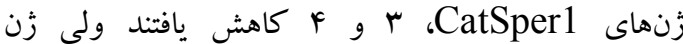
CatSper 2

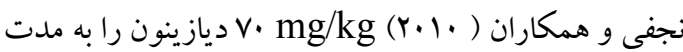

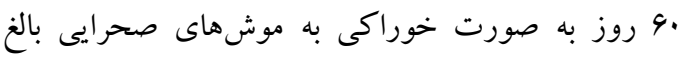

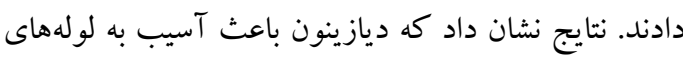
اسيرم ساز، آتروفى و نامنظم شدن آنها و نيز كاهش قطر و ضخامت ايى تليوم لولههاى اسبرم ساز شد. به علاوه ادم بافتى در ناحيه زير كيسول بيضه و بافت بينابينى مشاهده شد(·). ساز كار اين مطالعه، در تحقيق حاضر تزريق ديازينون باعث كاهش ضخامت إيى تليوم زرمينال شد.

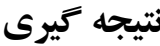

با جستجويى كه ما انجام داديم تاكنون مطالعهاى در مورد اثرات ديازينون بر بيان زن CatSper انجام نشده است. بتر بود در اين بزوهش بيان بروتئين CatSper1 توسط براس

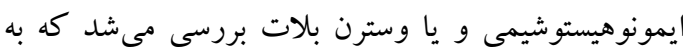

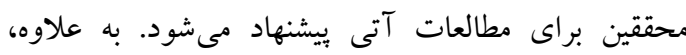

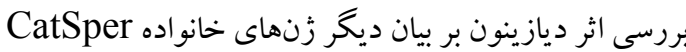
بيشنهاد مى گردد. نتيجه مطالعه حاضر نشان داد كه ديازينون با كاهش تحرك اسبرم و تغييرات درنراتيو در ابى تليوم

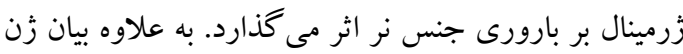

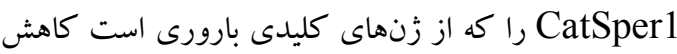

مىبايد.

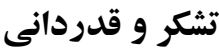

نتايج مطالعه حاضر نشان داد كه درصد تحر كك اسبرم پس از

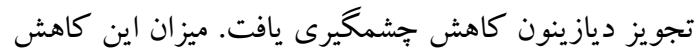
وابسته به دوز دريافتى ديازينون بود. جورسر ايى و همكاران

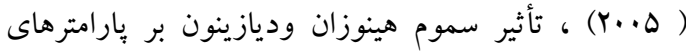

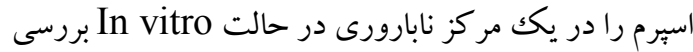
كردند. نتايج نشان داد كه اين سموم باعث كاهش تعداد و

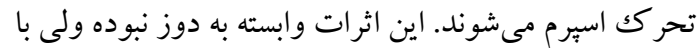

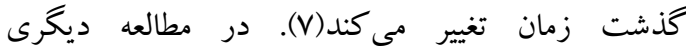
Okamura دريافت دوز mg/kg r ديازينون به مدت ه هفته باعث ايجاد قطره سيتويلاسمى در سر اسبرم، افزايش اسبرم شكسته به

$$
\text { و كاهش تحر كك اسبرم مىشود(^). }
$$

نتايج مطالعه Adamkovicova و همكاران ( 19 و.r) نشان r.mg/kg داد كه دوز F. mg/kg

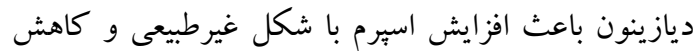
تحر كك اسبرم مىشود(9). Adamkovicova و همكاران

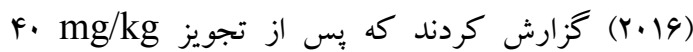
ديازينون، اسبرم با مرفولوزى غيرطبيعى افزايش يافت. به علاوه، تحر ك اسبرم كاهش يافت(1). ساز كار با تحقيقات بالا، در مطالعه حاضر نيز تزريق ديازينون باعث كاهش در تحر كك اسبرم شد.

در تحقيق حاضر كاهش معنىدارى در بيان زن CatSper1 mg/kg ور گروهاى دريافت كننده دوز V/ه mg/kg •r نسبت به گروه كنترل مشاهده شد. از بين زنهاى CatSper 1-4، زن CatSper1 كمتر دستخوش تغيير مى شود و از تنظيم زنى قوى ترى برخوردار است. محمدى و

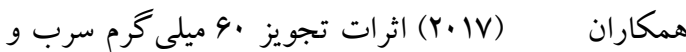

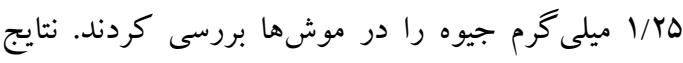

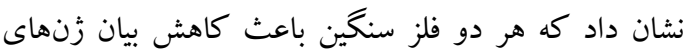
CatSper 1, 2 شديدتر بود. به علاوه تجويز اين دو ماده باعث كاهش 


$$
\begin{aligned}
& \text { نويسند كان مقاله بر خود لازم مىداند از كاركنان محترم دانشجوى كارشناسى ارشد زيست شناسى سلولى و مولكولى }
\end{aligned}
$$

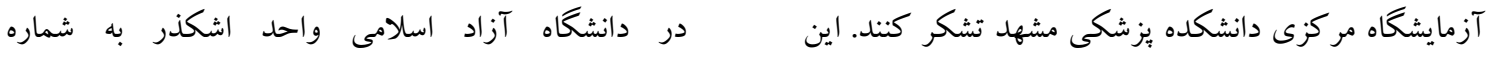

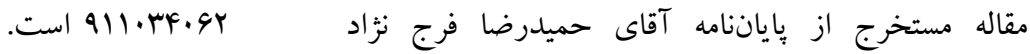

\section{References}

1. Hamidabadi HG, Pasbakhsh P, Amidi F, Soleimani M, Forouzandeh M, Sobhani A. Functional Concentrations of BMP4 on Differentiation of Mouse Embryonic Stem Cells to Primordial Germ Cells. Int J Fertil Steril. 2011;5(2):104-9.

2. Annelien Massart, Willy Lissens, Herman Tournaye, Katrien Stouffs Genetic causes of spermatogenic failure. Asian J Androl. 2012; 14(1): 40-48.

3. Piña-Guzmán B, Solís-Heredia MJ, Quintanilla-Vega B. Diazinon alters sperm chromatin structure in mice by phosphorylating nuclear protamines. Toxicol Appl Pharmacol. 2005 15;202(2):189-98.

4. Perry MJ, Venners SA, Barr DB, Xu X. Environmental pyrethroid and organophosphorus insecticide exposures and sperm concentration. Reprod Toxicol. 2007; 23: 113-8.

5. Wang D, Singhasemanon N, Goh KS. A review of diazinon use, contamination in surface waters, and regulatory actions in California across water years 1992-2014. Environ Monit Assess. 2017;189(7):310.

6. Taghavi R, Tavakoli Tabasi K, Mogharabian N, Asadpour A, Golchian A, Mohamadi S, Ataran Kabiri A. The Effect of Acupuncture on Relieving Pain after Inguinal Surgeries. Korean J Pain. 2013; 26(1): 46-50.

7. Jor Saraei G, Beiki A, Yousef Nia Pasha Y, Alizadeh Navaei R. The in vitro effects of Hinosan and Diazinon on human sperm parameters. JBUMS. 2005; 7 (2):30-34

8. Okamura A, Kamijima M, Ohtani K, Yamanoshita O, Nakamura D, Ito Y, Miyata M, Ueyama J, Suzuki T, Imai R, Takagi K, Nakajima T. Broken sperm, cytoplasmic droplets and reduced sperm motility are principal markers of decreased sperm quality due to organophosphorus pesticides in rats. J Occup Health. 2009;51(6):478-87.

9. Adamkovicova M, Toman R, Martiniakova M, Omelka R, Babosova R, Krajcovicova V1, Grosskopf B, Massanyi P. Sperm motility and morphology changes in rats exposed to cadmium and diazinon. Reprod Biol Endocrinol. 2016;14(1):42.

10. GR Najafi, S Salami, A Karimi. The effect of diazinon on testicular tissue in adult male rat: a histological study. J Urmia Univ Med Sci. 2010; 20 (4):313-319

11. Adamkovicova M, Toman R, Martiniakova M, Omelka R, Babosova R, Krajcovicova V, Grosskopf B, Massanyi P. Sperm motility and morphology changes in rats exposed to cadmium and diazinon. Reprod Biol Endocrinol. 2016;14(1):42.

12. Povey AC. Gene-environmental interactions and organophosphate toxicity. Toxicology. 2010;278(3):294-304.

13. Chávez JC, De la Vega-Beltrán JL, José O1, Torres P, Nishigaki T, Treviño CL, Darszon A. Acrosomal alkalization triggers $\mathrm{Ca} 2+$ release and acrosome reaction in mammalian spermatozoa. J Cell Physiol. 2018;233(6):4735-4747.

14. Beltrán C, Treviño CL, Mata-Martínez E, Chávez JC, Sánchez-Cárdenas C, Baker M, et al. Role of Ion Channels in the Sperm Acrosome Reaction. Adv Anat Embryol Cell Biol. 2016;220:35-69.

15. Jin SK, Yang WX. Factors and pathways involved in capacitation: how are they regulated? Oncotarget. 2017 10;8(2):3600-3627. 
16. Parodi J. Motility, viability, and calcium in the sperm cells. Syst Biol Reprod Med. 2014;60(2):65-71.

17- Quill TA, Sugden SA, Rossi KL, Doolittle LK, Hammer RE, Garbers D. A sperm ion channel required for sperm motility and male fertility. Nature. 2003;413:603-9

18. Ren D, Navarro B, Perez G, Jackson AC, Hsu S, Shi Q, et al. A sperm ion channel required for sperm motility and male fertility. Nature 2001; 413: 603-9 .

19. Quill TA, Sugden SA, Rossi KL, Doolittle JK, Hammer RE, Garbers DL. Hyperactivated sperm motility driven by CatSper2 is required for fertilization. Proc Natt Acad Sci. 2003; 100: $14869-74$.

20. Lobley A, Pierron V, Reynolds L, Allen L, Michalovich D. Identification of human and mouse CatSper3 and CatSper4 genes: characterization of a common interaction domain evidence for expression in testis. Reprod Biol Endocrinol 2003; 1: 53-68.

21. Liu J, Xia J, Cho KH, Clapham DE, Ren D. CatSper beta, a novel transmembrane protein in the CatSper channel complex. J Biol Chem 2007; 282:18945-52.

22. Wang H, Liu J, Cho KH, Ren D. A novel, single, transmembrane protein CATSPERG is associated with CATSPER1 channel protein. Biol Reprod 2009; 81:539-44.

23. Mohammadi Sh, Golamin M, Mohammadi M, Mansouri A, Mahmoodian R, Attari S, et al. Down-regulation of CatSper 1 and CatSper 2 genes by lead and mercury. Environ Toxicol Pharmacol. 2018; 59:82-6.

24. Mohammadi S, Gholamin M, Mansouri A, Mahmoodian RS, Babazadeh B, Kebriaei SM, et al. Effect of cadmium and nickel on expression of CatSper 1 and 2 genes in mice, Toxin Reviews, 2018; 37(3): 216-222, DOI: 10.1080/15569543.2017.1350192

25. Wang HF, Chang M, Peng TT, Yang Y, Li N, Luo T, et al. Exposure to Cadmium Impairs Sperm Functions by Reducing CatSper in Mice. Cell Physiol Biochem. 2017;42(1):44-54.

26. Mohammadi S, Rahmani F, Hasanian SM, Beheshti F, Akbari Oryani M, Ebrahimzadeh A, Farzadfar S. Effects of dioxin on testicular histopathology, sperm parameters, and CatSper2 gene and protein expression in Naval Medical Research Institute male mice. Andrologia. 2019; 11(51):1-7.

27. Attari S, Mohammadi S, Ebrahimzadeh A, Hosseinzadeh H, Soukhtanloo M, Rajabzadeh A. Effects of thymoquinone on sperm parameters, apoptosis, testosterone level, and oxidative stress in a mouse model of D-galactose-induced aging. Pharm Sci. 2018; 24(3): 180-186.

28. Pfaffl MW. A new mathematical model for relative quantification in real-time RT-PCR. Nucleic Acids Res. 2001; 1-29.

29. Mohammadi S. Protective Effect of N-Acetyl Cysteine Against Formaldehyde-Induced Neuronal Damage in Cerebellum of Mice. Pharmaceutical sciences. 2014; 20: 61-65. 